\title{
The Form and Content of Recent Riots
}

\author{
Hans W. Mattick
}

The Report of the National Advisory Committee on Civil Disorders, Tom Wicker has written, "derives its most devastating validity from the fact that it was drawn by representatives of the moderate and 'responsible' establishment-not by black radicals, militant youth or even academic leftists." 1 No doubt Wicker is right, but, despite its laudable desire to "tell it like it is," the Commission was not insensitive to presumed political constraints. In the analytic parts of the Report the war in Vietnam, as a contributory factor to unrest in the nation and as a diversion of national resources, was all but ignored. Similarly, there was no discussion of the fiscal problems involved in implementing the Commission's recommendations for social change. ${ }^{2}$

Hans W. Mattick is Associate Director, Center for Studies in Criminal Justice, the University of Chicago Law School, and was employed by the National Advisory Commission on Civil Disorders to do research on the sociological aspects of riots under OEO Contract B89-4353 during the period January 22 to March 1, 1968. An earlier version of this article appeared in the Summer 1968 issue of Midway, published by the University of Chicago Press, whose cooperation is gratefully acknowledged.

1 The Report of the National Advisory Commission on Grvil Disorders v (Bantam Books ed. 1968).

2 The most comprehensive study of riots (as distinguished from studies of revolutions) in the pre-1960 period states: "The five most bitter race riots in this century have been those of East St. Louis, Washington, Chicago, Tulsa and Detroit. Each of these riots has occurred either immediately before, during, or immediately after a major war involving the United States. The hypothesis might legitimately be raised that these disturbances have been reflections of a generalized climate of violence which results from wartime conditions." A. Grimshaw, A Study in Social Violence: Urban Race Riots in the United States 180 (unpublished doctoral dissertation, Dep't. of Sociology, Univ. of Pennsylvania, 1959). The Commission resisted the temptation to contribute to a further test of this "legitimate hypothesis," but this will no more deter future students of riots from considering all relevant facts than it has scholars in the past. The association between wartime conditions and the outbreak of civil disorders is a historical fact frequently commented upon by social historians. Cf. L. Edwards, The Natural History of Revolution (1927); C. Brinton, The Anatomy of Revolution (1938).

The decision to issue the report in March rather than July, as originally planned, although it seriously compromised the quality of much of the Commission's work that had been predicated on the longer timetable, no doubt reflects a political decision of a different order. The six months between the foreshortened publication date and the national political conventions in August may have been viewed as a sufficient "cooling off" period to help moderate the effects of the report on either the political conventions or the public or both. Neither subsequent events nor the political activities of "outsider" 
Just as the Commission displayed a tacit circumspection about the hard realities of war and money in relation to the President and Congress, the senior staff of the Commission displayed a cautionary sense about the presumed limits of ideological tolerance of the Commissioners. The senior staff, all bright, knowledgeable, and ambitious young men, organized the working drafts from materials supplied by the lower staff levels and more than two hundred "Consultants, Contractors, and Advisors." It was the senior staff that decided what materials would be allowed to remain in the final drafts submitted to the Commission for review, acceptance, or rejection. Whether they were any more accurate in their perceptions about the Commissioners than the latter were about the President and the Congress, is an unanswerable question, but this entire process of anticipation and the exercise of restrained sensibilities underlines the conservative nature of the Report.

In practical terms this means that very little got into the analytic parts of the Report that could not be documented by defined data, explicit methodology, sworn testimony, affidavits, or very reliable sources. Chapter 2, "Patterns of Disorder," with its 249 explicit footnotes, is only the most obvious example of this passion for "sticking to the facts" as closely as possible while pointing to the data, its methodology, and its sources. While this resulted in the publication of a great deal of material that may be useful to future scholars, it was a process of exclusion as well as inclusion. The manifest aspects of civil disorders were set forth in great detail; their latent aspects were relatively neglected. The tendency to generalize, to interpret "the facts," was, by and large, resisted as too speculative an enterprise for a governmental commission. As a consequence, several interesting attempts to formulate a riot typology, based on data available to the Commission, simply did not survive the division of labor and editorial decision processes that resulted in the published Report. ${ }^{3}$ In what follows, the tendency to generalize will be given a limited scope, an interpretation of some of the facts will

groups, however, were as readily controllable as the publication date of the report, as witness the disorders following the assassination of Dr. Martin Luther King, Jr.

3 Two other such attempts came to the author's attention. One was prepared by Robert Shellow, Assistant Deputy Director of Research for the Commission, in an excellent paper entitled "The Harvest of American Racism," which was prominently stamped with the cautionary message: "This document has been neither submitted to, nor approved by, the members of the Commission." The other was prepared by John $R$. Spiegel, Director, Lemberg Center for the Study of Violence, Brandeis University, who is listed among the "Consultants, Contractors, and Advisors" to the Commission. Hopefully, both of these papers will be published in order to contribute to the public understanding of recent civil disorders. 
be made, and a typology of both the form and the content of the riot process will be presented.

\section{Givil Disorders Since World War II}

The central fact about civil disorders is that they are an interruption of the orderly processes of human life. In almost every dimension they have been unusual, irregular, and, in the present state of our knowledge, unpredictable. This is not to assert that civil disorders are beyond the grasp of understanding or the norms of human behavior, but rather that the conditions which bring them to pass are both numerous and complex. In our attempt to understand civil disorder-to comprehend what is happening and, insofar as possible, why it is happening-we must consider these conditions in an interrelated fashion.

The three safest generalizations that may be drawn from the civil disorders since World War II are all negative: (1) There is really no such entity or process as a typical civil disorder. Any attempt to construct ideal-types of the form or content of riots must abstract and combine predominant tendencies. (2) Although the civil disorders since World War II have been racial in character, they have not been interracial. In contrast to the interracial conflicts that erupted occasionally from the colonial period through World War II, in which groups of one race came into direct conflict with groups of another, recent civil disorders, including those of 1967, have been directed against the local symbols of white American society: authority and property. (3) Despite the extremist rhetoric of some unimportant fringe groups, there has been no serious, systematic attempt, either actual or ideological, to subvert the democratic and pluralistic social order of the United States. In effect, what those who are now attacking white authority and property are saying (and have been saying for the past hundred years) is, "We want fuller participation in the goods, services, and amenities enjoyed by the vast majority of American citizens." In this sense, the conflict between the majority and the minorities represents a conservative movement. At this juncture in history the remaining minorities still want "in," not out; they want to play a role in the American dream, not create a nightmare of the extreme right or left.

\section{Elements To Be Combined in a Typology}

While all of the Commission's findings may be drawn upon for a typology of riots, some aspects of its analysis are more useful than others. For the first nine months of 1967 the Commission compiled a list of 164 civil disorders occurring in 128 cities. These were classified 
by the criteria of levels of damage and violence into "major," "serious," and "minor" civil disorders, and then subclassified by month, region, and population size of cities in which they occurred.4 In addition, the Commission made a detailed study of twenty-four civil disorders in twenty-three cities; ${ }^{5}$ conducted more than 1,200 interviews in twenty cities to study the content, frequency, and intensity of grievances in Negro communities; ${ }^{6}$ and made a special study of riot participants based on all the foregoing, supplemented by arrest records and two probability samples from Detroit and Newark. ${ }^{7}$ These parts of the Commission's Report are singled out because they are important baselines and constitute the source materials for what follows. Although the Commission's conclusions are clear, an examination of its analysis will reveal that questions related to the causes, motives, and objectives of the riots remain implicit. The only distinctions made among riots are those based on low-level intensity scales of quantifiable factors. The Commission's grievance study, the detailed study of twenty-four disorders, and the studies of the riot participant will enable us to be more explicit and to make some qualitative distinctions. At the same time, the Commission's classifications of the 164 civil disorders will tend to limit any generalizations incident to the construction of a riot typology.

In proportion to the degree to which one is familiar with the complexity and interrelated details of civil disorders, one is prevented from drawing easy generalizations about such involved social processes. We are engaged in an enterprise of vast oversimplification in which we shall emphasize the central tendencies of manifest and latent social phenomena. We can only do. what the nature of the data reasonably permits. The riot processes we will try to describe have multiple facets, contradictory movements, elements that have been ill-defined, misjudged, and unknown. The task before us can only result in a product based on limited, though informed, judgment.

The twenty-four disorders in twenty-three cities studied in detail by the Commission revealed only the most general and elementary uniformities directly deducible from time and place, challenge and response, ambiguous beginnings and indeterminate ends. Each was a

4 Report of the National Advisory Commission on Crvir Disorders 65-66 (Govt. Printing Office ed. 1968) [hereinafter this official document will be cited as NACCD REPORT].

6 Id. at 67. The twenty cities and three university settings were: Atlanta, Bridgeton, Cambridge, Cincinnati (June disorder); Dayton (June and September disorders); Detroit, Elizabeth, Englewood, Grand Rapids, Jersey City, Milwaukee, Newark, New Brunswick, New Haven, Paterson, Phoenix, Plainfield, Rockford, Tampa, and Tucson; Houston (Texas Southern University), Jackson, Miss. (Jackson State College), and Nashville (Fisk University and Tennessee A. \& T. State College).

6 Id. at 80-83.

7 Id. at 73-77. 
process of social interaction developing over a period of time out of an increasing state of grievance and tension on the part of the Negro community, and a correlative degree of apprehension on the part of the white community, particularly as reflected in a series of police incidents. ${ }^{8}$ As tensions increased, a variety of attempts were made to achieve new, or maintain old, levels of racial accommodation. As these attempts broke down, the potential for violence increased, resulting in a variety of explosions related to the cluster of circumstances and social forces that characterized the particular locale and its problems.

In the majority of cases a particular confrontation can be labeled the "precipitating incident" that apparently preceded the eruption of violence; but in almost all cases there had also been a series of prior incidents that, in their cumulative impact, merged into the last of the series. Whether these earlier incidents happened a few days, or a month, or a year or more before, they all contributed directly to the increasing grievance and tension in the Negro community and helped precipitate violence. Once violence was abroad, it varied widely from city to city in intensity, duration, and quality over time. ${ }^{9}$

\section{The Grievance Bank: Gauses and Motives}

If riots were merely the irrational expression of a perverse human nature, we would have to ask ourselves: Why Watts rather than Beverly Hills in Los Angeles? Why the Central Ward rather than some outlying ward in Newark? And why Twelfth Street in Detroit rather than Grosse Pointe? But riots do not simply "break out" in a "spontaneous" fashion in a previously calm environment. Their antecedents lie deep in the history of race relations in the United States ${ }^{10}$ and in the perceptions of living men of that history and of their own experiences.

If a number of men have similar experiences with similar reactions, and they share their experiences and memories with others, the basis has been created for a community of interest whose common denominator is a set of shared conceptions. If a disproportionate amount of these shared experiences and memories are of pain, disappointment, and anger, the men will consider themselves aggrieved. This is the situation of the Negro community in the United States and, to a greater or lesser degree, the situation of other disadvantaged minorities. It is worth noting that everyone, including the white majority, has some grievances. They may be less demonstrable in an objective fashion, less widely or

8 Id. at $68-71,80-83$.

9 Cf. "Charts on Levels of Violence and Negotiations," id. at 359-407.

10 The best single analysis of race relations in this country is to be found in G. MYrDar, AN AMERican DILEMLAa (1944). 
intensely shared, and are therefore less likely to form the basis for a community of interest. Insofar as they have a racial focus, however, they can play an important part in contributing to violence.

Reference has been made to the Commission's study of the content, frequency, and intensity of grievances in the Negro community. Here we are mainly concerned with the qualitative nature of these grievances, the relationships between them, and how they interact with other social processes to form what we will call the grievance bank. The grievance bank may be conceived of as a combined metaphor, including elements of a memory bank, a data bank, and an exchange bank, with inputs and outputs that accumulate, draw variable interest, and convert into each other through actual or symbolic forms of exchange.

A grievance bank, whether that of the Negro minority or the white majority, contains an intricately related set of factors which may be separated conceptually into three types: (1) objective factors; (2) mixed objective and subjective factors, that is, subjective perceptions and values placed on the objective factors; and (3) purely subjective factors. The main difference between the Negro and white grievance banks, as will soon be apparent, is that on the average the values that can be assigned to the more objective factors are higher or positive for whites and lower or negative for Negroes, while the values that can be assigned to the more subjective factors are similar in their intensity or central tendency.

1. The Objective Factors. The objective factors, as the term implies, are those on which there is substantial agreement. They have a high degree of validity and reliability, and separate investigations into their essential nature would result in similar findings. They can be classified, counted, defined, and described with a high degree of precision. Specifically, they include: the population characteristics of a defined area, income levels, employment rates, housing conditions, educational achievement, physical and mental health, recreation facilities, political representation, the administration of justice, welfare services, municipal services, and commercial practices. Attitudes and future promises and threats enter only indirectly, if at all, into the objective factors in the grievance bank.

2. The Mixed Factors. The mixed factors are products of individual or group judgments of events and conditions. These judgments are derived from the perception of events and the subsequent interpretation of the events as perceived. The perception and its interpretation may be accurate or distorted, but, in either case, they are largely determined by the social position and function of the individual or group. This is the area in which the attitudes of whites and blacks di- 
verge most sharply. In the Negro grievance bank, these factors are given negative values. Specifically, these mixed factors include: demeaning or "brutal" police incidents; low wages, unemployment, underemployment, and job discrimination; poor housing in bad areas; substandard schools without quality education; ill health and mental stress; disorganized family life; inadequate recreation facilities; underrepresentation and political exploitation; a double standard in the administration of justice; inadequate and demeaning welfare services; lack of municipal services resulting in dirt and rats; unfair credit and commercial exploitation; and prejudicial white attitudes.

3. The Purely Subjective Factors. The purely subjective factors are myths, rationalizations, and paranoid projections based on the other two sets of factors in the grievance bank. This is the sphere of rumor, propaganda, conspiratorial "plans," and political agitation; the realm of political opportunism, charismatic rhetoric, threats and promises addressed to the future, and the folklore of the streets. It is that proportion of ideology which is designed to appeal to the emotions rather than reason and which, while it may move men, moves them in unpredictable ways. In contrast to the objective and mixed factors, these purely subjective factors are sound and fury signifying relatively little.

These are the contents of the grievance bank of the Negro community. They constitute the social forces that motivate some Negroes to challenge the existing level of social accommodation or to act violently. Similar social forces contribute to the motivations of the white majority and move some whites to resist any challenge to the present level of social accommodation.

Since our pluralistic and democratic society is constitutionally grounded on a division of powers between the three major branches of government through a system of checks and balances, it can, for purposes of constructing an ideal-type, be defined as approximating an unstable equilibrium model of social organization. Such a society tends to exercise minimal controls over social forces. Competitive processes in the economic sphere are, for the most part, regulated by market conditions; in the political sphere they are determined by numbers, power, influence, and negotiation; and in the social sphere they are controlled through voluntary association and informal channels of communication. Competition and interaction among such social forces tend to result in a relatively stable level of accommodation between majority and minority interest groups. The same competition and interaction also result in social change, tending to upset that level of social accommodation. But when the more peaceful mechanisms of social control break down, or are not responsive to the needs and de- 
mands of competitive interests, the stage is set for potential violence.

Ordinarily, there is resort first to the civil law, and then to the criminal law, in a final attempt to contain the potential violence. If, however, the law, in its ultimate role as the arbiter of justice, is itself perceived as being unresponsive or contaminated with prejudice, the potential for violence is increased. In the construction of the grievance bank and, much more thoroughly, in the Commission's study of the intensity of grievances, the importance and salience of Negro grievances about police incidents are manifest. This is the sensitive area that more frequently than any other was the occasion for the eruption of violence in the civil disorders of 1967.

Thus, our inferred "causal chain" begins with a postulate of grievance based on objective factors, leading to an increase in social tension; attempts at challenging the existing level of social accommodation; the achievement of a new and more satisfactory level or, failing that, the maintenance of the old level, or even a less satisfactory one; and renewed cycles of challenge and response, until a viable equilibrium with satisfactory adjustment and continuity is achieved. Like most causal analyses of social phenomena, it is not definitive; but it is not an unreasonable inference in the light of the civil disorders that disturbed the nation last year.

The objective factors in the grievance bank may therefore be conceived of as "causes," and the mixed factors as "motives." This is not to assert that unitary causes lead to simple motives that move men to precipitate riots, nor is it to deny that the purely subjective factors in the grievance bank make a significant contribution to the eruption of violence. On the contrary, it is necessary to emphasize that many causes and motives combine in diverse ways, under various conditions, in differing settings; and yet whether violence erupts or not still remains problematic. More frequently than not, the question turns on the nature of the response from the side of authority. Indeed, in some cases violence is precipitated by the anticipatory behavior on the part of an overapprehensive authority.

More generally, however, a community of interest whose common denominator is a set of shared grievances contains enough free-floating hostility seeking a target or a scapegoat that the potential for violence is always present. Given an indeterminate amount of such free-floating hostility, combined with an apprehensive authority that tends to identify with the aggrieved portion of the white majority (which is also seeking an outlet for its hostilities), under the conditions of a precipitating incident and the rehearsal of past grievances, the outcome is civil disorder. All of the foregoing must enter, to a greater or lesser ex- 


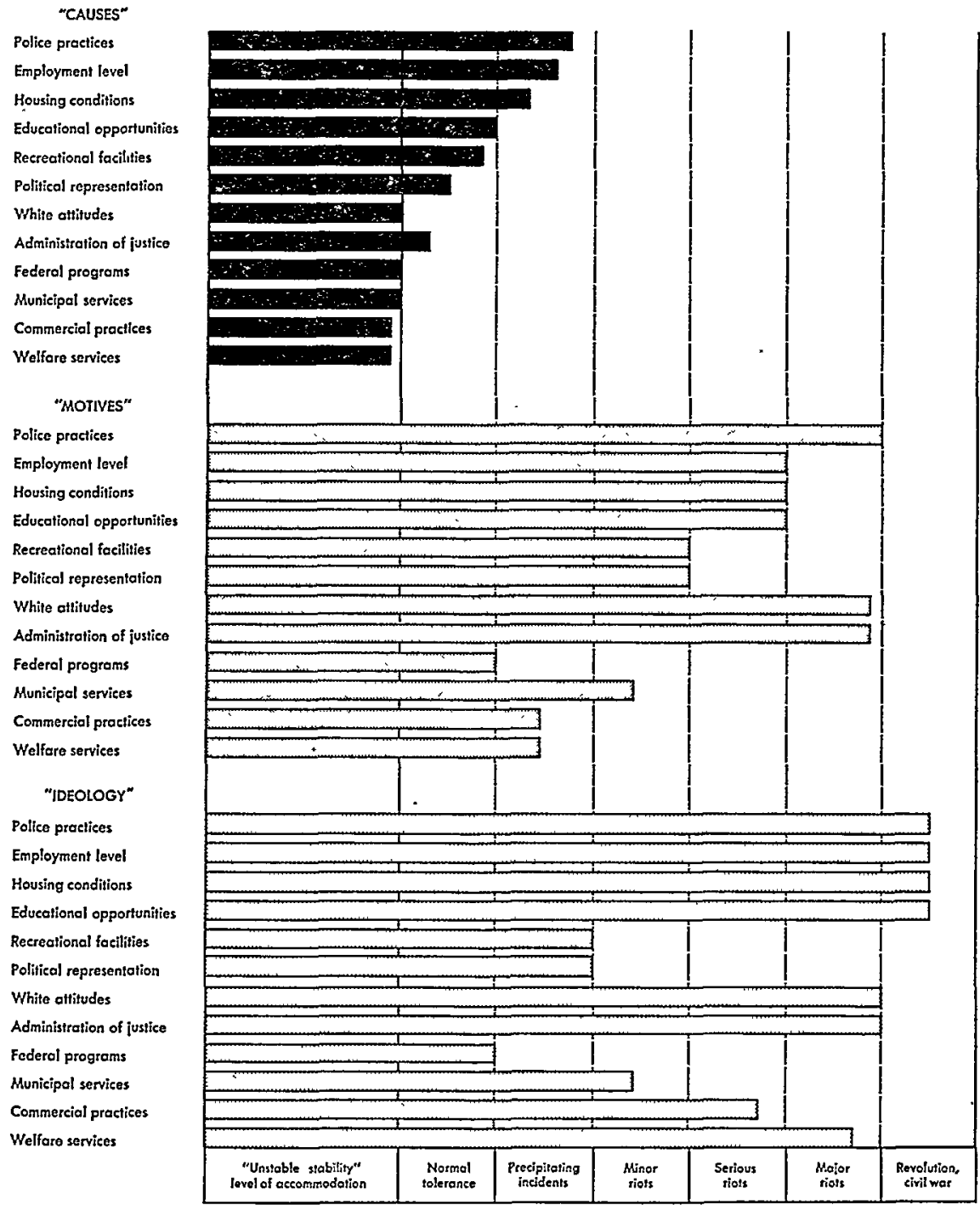

Figure 1. Grievanctes and Potential Behavior in an Unstable Equilibrium Model of Social ORganization. In this model the social forces interacting in the "grievance bank," and tending toward increasing levels of social instability, are classified in terms of intensity and seriousness. The more "objective factors," which are measurable, valid, reliable, and existential, are defined as "causes." The "mixed objective and subjective factors," which are structured perceptions of objective factors that are value-judged subjectively, are defined as "motives." The more "subjective factors," which are myths, rationalizations, opportunistic rhetoric, and street folklore, are defined as "ideology," that is, largely irrational. The dimension from left to right indicates increasing intensity and the dimension from top to bottom indicates decreasing seriousness. The darkness of shading suggests the relative potential seriousness of the three groups of factors. 
tent, into the typology of the form and content of the riot we propose to construct.

\section{Some Limitations on Generalizations}

The Commission reported that, because of widely varying definitions, "between 51 and 217 disorders were recorded by various agencies as having occurred during the first 9 months of 1967. From these sources we have developed a list of 164 disorders which occurred during that period." 11 It was this sample of 164 "civil disorders," occurring in 128 cities, which was classified in readily quantifiable ways. When the Commission made its careful inquiry into the riot process, concluding that "the differences between various disorders were more pronounced than the similarities,"12 it "examined 24 disorders which occurred during 1967 in 20 cities and three university settings." 13 Since we intend to draw upon the data and descriptions of the latter in the development of our typology, it is necessary to compare the sample of 164 with the sample of twenty-four, by the Commission's own classifications, in order to note any important differences. (See table on page 670.)

The most important differences between the larger and smaller samples of disorders are that the smaller sample is heavily weighted in the direction of greater seriousness and larger cities. Most of the six major and ten serious riots, in contrast to the eight minor ones, ${ }^{14}$ occurred in large urban locations with many agencies and observers to record information and supply testimony. Any generalizations derived from such a biased sample are apt to mislead the reader about the character of civil disorders in general and contribute to a greater degree of public apprehension than the facts warrant. This will tend to lend to our analysis and generalizations a decidedly serious and urban cast, but it is not intended to imply a necessary correlation.

Despite these reemphasized cautions, we will utilize the major riot as a methodological device to generalize about riot processes. A major

11 NACCD REPORT at 65.

12 Id. at 67. We do not quarrel with the Commission which admits that it "found a common social process operating in all 24 disorders in certain critical respects. . . . [But] the differences between various disorders were more pronounced than the similarities." Id. But there is a difference between history and sociology. Sociology seeks to generalize from history and contemporary social life, and so long as assumptions, hypotheses, and methods are made reasonably explicit, rational discussion can go forward about the adequacy of the generalizations that are derived from human experience.

13 Id. See note 5 supra.

14 "Major": Cincinnati, Detroit, Milwaukee, Newark, Plainfield, and Tampa. "Serious": Atlanta, Cambridge, Dayton (June), Grand Rapids, Houston, Jackson, Nashville, New Haven, Paterson, and Phoenix. "Minor": Bridgeton, Dayton (September), Elizabeth, Englewood, Jersey City, New Brunswick, Rockford, and Tucson. 
Comparison of Two Samples of Crvil Disorders

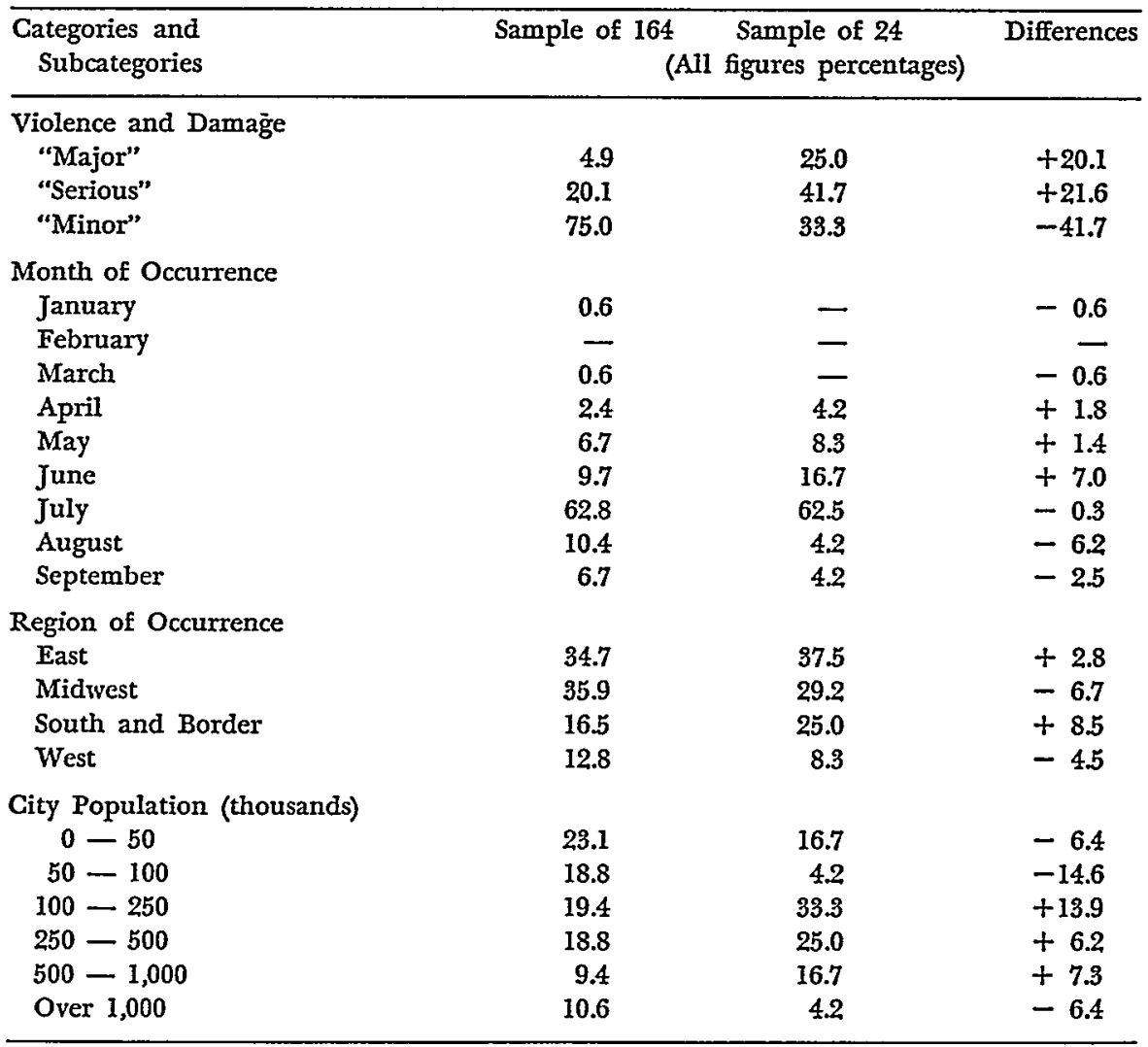

Source: NACCD REPORT at 66 and 324-25 nn. 7, 8, 11.

riot is an enormously complex social phenomenon with mixed causes, motives, and objectives. Therefore, we must resort to a process of abstraction, which makes possible conceptual separations from a combined reality. In so doing, we are imposing logic; we are not recreating reality. In our typology we will present the predominant character of some riots and combine elements or strains from several riots in order to exemplify the central tendencies of different kinds of riots.

Our method will be to present first the form and then the content of the riot. The form of the riot will describe the most general social processes that occur, quite apart from any particular time, place, or person. It will appear to be the chronological sequence of a major riot that runs its course. Only the most general and neutral labels of identification for the participants and contributors will be used, and events will be set forth in an impersonal fashion. In using a major riot as a methodological strategy we do not mean to imply that serious or minor civil disturbances are interrupted or aborted major riots. A civil dis- 
turbance is an emergent situation and what its ultimate character or course might have been, in the absence or presence of events that did not occur, must remain unknown.

\section{The Form of the Major Riot: Soclal Processes}

The form of the riot is symmetrical. It consists of challenges and responses between the official and the private participants to the riot, with the interchange originating, potentially, from either side. Within this predominant pattern there are contributors and participants who are only indirectly involved, but who, from time to time, help determine the general course of events. Included in the definition of official participants are: local, state, and national officials, especially the police and the military. Private participants include local citizens, members and leaders of local community organizations, curious outsiders, and petty criminals. The indirect contributors are the mass media, counterrioters, irrational opportunists, and discussants and negotiators, who may be somewhat removed in space and social distance but are trying to affect the course of events. There is, obviously, some overlap and interchange among these categories; some persons play both formal and informal and active and passive roles in the entire process.

\section{An Ideal-Typical Riot Process}

1. The Final Incident occurs: there is acute interaction between some official and private persons in the presence of an initial audience.

2. The First Violence erupts: the official and private persons conflict, with some degree of audience participation; the initial audience grows tense, but the official and private participants diverge, usually leaving each other's presence.

3. The Inter-Stimulation and Early Definition Process:

a. The private group intra-acts and increases in number through communication and movement.

b. The official group intra-acts and increases in number through communication and movement. social process.

c. Both groups seek to "define" the ambiguous, emergent

4. The Mass Media, first electronic and then printed, report the event, including the early definitions gained from official sources.

5. The Conflict Preparation Process:

a. The private group congregates at the original scene or migrates to the location of the official group. Intra-stimulation, communication, feedback, and movement increase tension.

b. The official group returns to the original scene or meets the 
private group at the migration location. Intra-stimulation, communications, feedback, and movement increase tension.

c. Conflicting definitions of the situation are voiced. Complaints, demands, threats, and insults are exchanged in the presence of an audience.

6. The Second Incident occurs: uncontrolled elements in the official and private groups interact intensely and acutely in the presence of a larger audience.

7. The Second Violence erupts: the official and private groups conflict and diverge; the entire audience, official and private, is highly stimulated and seeks an outlet for the increasing tensions.

8. The Mass Media continue to report these events with the selection of dramatic elements in headlines and pictures. News sources are both official and private, and the early definitions of the situation are qualified.

9. Both the official and private participants, and many members of the larger audience, activate their full communication spheres, formal and informal, and receive feedback that contributes to further stimulation and tension.

10. Unofficial counter-rioters and irrational opportunists intervene and attempt to decrease or increase the level of violence and tension by redefining the situation.

11. In the background, near the scene of action or removed from it, putative leaders and representatives of both the private and official participants meet to discuss, define, and control the riot. Formal statements of demand and response are made, threats and promises are voiced, some negotiations begin, and tactical, non-violent plans are formulated.

12. Preparations for the Final Resolution or Exhaustion:

a. The official group rallies non-local forces to the scene of greatest potential danger or violence in order to deal with it.

b. The private group is congregated at, or gravitating toward, the scene of final confrontation.

i. The official group has increased in number, changed its basic identity and behavior, and becomes both more threatening and more impersonal (non-local-usually state police, National Guard, or federal military forces).

ii. The private group has increased in number, changed some elements of its identity and behavior, and responds more impersonally to the new authority (more older persons, more crimes of opportunity, officially recognized counter-rioters).

13. The Final Confrontation: 
a. The official group disperses or contains the riot participants, or withdraws from the scene of interaction.

b. The private group interacts and intra-acts intensely in response to the actions of the official group.

c. There is violence and destruction on both sides, unless the official group has withdrawn, in which case there is destruction and looting within the riot area.

14. The Mass Media report more objectively about events, including violence, counter-violence, background meetings, and negotiations. Some "in depth" reports are included with the "news."

15. The Terminal Process:

a. The private group begins to resume normal routines, with diminishing frequency of contact with authorities. Basic human needs for food, shelter, and safety assert themselves.

b. The official group begins a withdrawal pattern and transfer of responsibility and identity to local authority.

c. Peaceful emergency measures are taken, on both sides, to deal with the immediate consequences.

16. Plans for the future are formulated by representatives of the official and private groups together, and by some members of the official and private groups separately.

a. Cooperative plans are formulated with full participation and democratic process.

b. A facade of planning, using the rhetoric of cooperation, is enacted with many reservations on both sides.

i. "We will all do our best for a peaceful future together."

ii. "Next time we'll really get the dirty bastards."

The Content of the Major Riot:

Economic, Political, and Irrational Processes

The riot erupts from an existing level of accommodation between the Negro and white communities. Over time, the Negro community experiences unfair treatment at the hands of the white majority, and grievances accumulate. Attempts to redress these grievances through formal channels are unsuccessful because of an unequal distribution of power as well as myths about the inferiority of Negroes; grievances are denied, minimized, or rationalized. Changes in the formal law are only partially successful in answering these grievances, and are a grudging, rearguard action. Nevertheless, such changes are represented as progress, while informal procedures are devised to subvert the formal changes in the law. The law has moved too slowly, done too little. Grievances continue to accumulate; soon the grievance bank of the 
Negro community is full. At this juncture, after a series of similar incidents, the final incident occurs, and violence erupts.

Any attempt to understand the nature of a riot by observing only final incidents is, more often than not, to deal with symptoms rather than causes. Indeed, final incidents are routine if not trivial. They are recalled in retrospect because they happen to have been the occasion for the eruption of violence; otherwise, they resemble ordinary events. But the causes, motives, and factors that contribute to the momentum of a riot emanate from the grievance bank of the Negro community. And, while there is no simple or direct line of progression from cause to motive to action, groups of related grievances can be converted into clusters of causes that motivate men to actions that result in riots. From this moving image of social process and content, an immensely complex phenomenon, we can construct a number of ideal-types. The methodological strategy that we shall adopt is to name a heuristic type, to describe its qualitative content, and to point to examples among the twenty-four civil disorders of 1967 especially studied by the Commission.

\section{Ideal-Typical Riots Classified by Content}

1. The "Rational" Riot of a "Rising" Negro Class. The "rational" riot is "rational" in the sense that, from a confused, emergent situation, collective purposes of a "realistic" nature become clear over time, and means are relatable to ends. The rioters and their sympathizers, to a greater or lesser degree, attempt to achieve these ends. Such riots tend to take place in nonsouthern metropolitan centers. When the setting is southern, its regional characteristics are often offset by the presence of a university or large-scale student participation: Such riots tend to have longer periods of duration during which their objectives become increasingly clarified. They tend to be preceded or accompanied by new or intensified competition among leadership elements within the Negro community, in addition to leadership struggles between elements of the black and white communities. These competitive strivings follow the major leadership dimensions: young and old, radical and conservative, and black-dominated and white-dominated ideological values. During the course of the riot the leadership structure and ideology within the Negro community tends to shift toward the young, radical, black ideology. In response, the white leadership tends to make some public concessions to the traditional Negro leadership in an attempt to subvert the new, rising black leadership and its more radical demands. Participation in the riot involves large numbers and generates widespread sympathy in the Negro community. Both the rioters and their sympa- 
thizers become increasingly task-oriented over time, relating basic causes and motives to short- and long-term objectives. The participants in the rational riot tend to change in identity and character over time. In the early stages of the riot they are younger, less firmly related to the local and wider social structure, and more likely to run great risks and engage in actual and symbolic acts of aggression and defiance. In the later stages of the riot, the participants tend to be older, more firmly rooted in the local and wider social structure (in terms, for example, of family relations, employment and prior legitimate behavior), and they are less likely to engage in irresponsible actions. The participants in a rational riot and their sympathizers are better educated, more politically aware, and slightly better off financially than a true underclass. They are also more self-aware and identify more with the mystique of black power and cultural negritude. In descending order of preference, they refer to themselves as black rather than Negro, and Negro rather than colored. The causes that emerge over time are related to the objective factors in the grievance bank-employment, housing, education, political representation, administration of justice, etc. The motives that members of the Negro community exhibit and verbalize tend to stress the more objective among the mixed factors in the grievance bankpolice brutality, low income, unemployment and job discrimination, poor housing and untoward effects of urban renewal, substandard schools with low-quality education, etc. The purely subjective factors in the grievance bank-propaganda, agitation, conspiracy, etc.-add fuel to the riot, but contribute nothing new. Both violence and rationality assert themselves in a complementary fashion. Immediately before and in the early stages of the riot, the Negro community sees the white majority, and particularly its local representatives, as unresponsive to claims, with channels of communication blocked. During the riot, some elements of both the Negro and white communities seek opportunities for meetings where more rational discussion and some negotiation of salient grievances can be undertaken. Such meetings tend to alternate with periods of violence, almost as if violence, or the threat of violence, were the medium of exchange in a bargaining session. The new leadership structure that tends to come to the fore in a rational riot participates to a greater degree in such meetings and negotiations; there is more youthful, radical, and black-ideological representation in these attempts to communicate. On the streets, however, in the violent interaction, there is a greater tendency on the part of local authority to engage in retaliatiory violence, but this is soon brought under control by the arrival of outside military forces. As the rational riot wanes and begins to pass into its aftermath, the Negro 
community has outlined a fairly clear set of economic, political, and legal proposals for change, and there is at least an initial disposition on the part of the white power structure to address them seriously, within the limits of political survival. ${ }^{15}$

2. The "Expressive" Riot of a Negro "Underclass." The expressive riot is a "sentimental" riot in the sense that it is a cathartic release of accumulated feelings and attitudes. While these riots have latent causes and motives, they do not emerge clearly. The predominant character of the riot remains an expression of sentiments. As a consequence, the objectives of the riot are not formulated in sufficiently general terms to achieve consensus on more rational action; or the apparent objective is a specific, local facet of a more general problem that is not focused upon. The latter may be a direct reaction to the final incident, that is, to a symptom; or it may be a high degree of preoccupation with, for example, the failure to serve Negroes in a particular restaurant, rather than the more general problem of equal access to public accommodations. With such unclear or highly specific objectives, resistance to change is usually successful in the short run. As a result, the level of fension and frustration either has no clear target or the identified target represents an aggravating defiance. The feelings of frustration are first dammed up, then overflow into action that becomes violent. Such riots tend to take place in southern, less urban locations, especially southern university towns with largely non-local student populations. The deprivation of the Negroes involved in such riots may, but does not have to, be absolute; rather, the participants may belong to a socially mobile group that feels relatively deprived in comparison with white peer groups. Black consciousness characterizes the relatively deprived group, but is absent or denied in the true underclass. The former identify themselves as black, the latter as colored. Expressive riots are also preceded, or accompanied, by competition among leadership elements in the Negro community but have a relative absence of competition for leadership between blacks and whites. The leadership struggles are intergenerational and largely ideological. The older Negro leader̂́

15 With due regard to the necessary qualifications imposed by the internal complexities of all riots, nevertheless the following classification of riots into our typology is hazarded here and in the next three footnotes infra. The major riots in Cincinnati, Detroit, and Newark are the best examples of "rational" riots among the twenty-four civil disorders under consideration. The major riot in Plainfield, the serious riot in New Haven, and the minor riots in Englewood and New Brunswick also exhibited strong "rational" themes. The three serious riots in university settings, Houston, Jackson, and Nashville, while including some "rational" themes, are classified as "expressive" (see note 16 infra) because the riot participants lacked a sufficiently firm community base to be taken seriously by the local white power structure. 
that obtains between the races; the younger black leadership is challenging these traditional leaders. But, whether the participants in an expressive riot are a true underclass or perceive themselves as such in terms of relative deprivation, neither group has sufficient power locally to elicit a serious response from the representatives of the white power structure. The true underclass is ordinarily disorganized and apathetic, and the relatively deprived group is young and nonresidential. Participation in the riot is numerically small, generates great hostility among whites, and arouses little sympathy in the wider Negro community. The expressive riot is shorter than the rational riot. After the incident of first violence, the expressive riot is kept alive by large infusions of purely subjective factors in the grievance bank: rumors, propaganda, political agitation, and the folklore of the streets. These are retailed in the streets by temporarily charismatic rhetoricians or by student speakers and nationally prominent black militants invited to participate in the local protest. The identity and character of the rioters does not change over time, or from prior incidents to the current incident. Such causes as emerge in the course of the riot are closely related to the motives for action; they flow from the more subjective among the mixed factors in the grievance bank, such as discriminatory behavior and prejudicial attitudes of whites. Attempts to communicate and negotiate with the leaders in the white power structure seldom succeed; instead the meetings and negotiations that occur are mediated through middle-range representatives (both black and white) of the white majority, for example, school superintendents, police captains, aldermen, or a top executive's assistant. The relationship between such meetings and the violence in the streets is remote, however, for the white leadership sees the violence as a problem to be dealt with by major reliance on repressive measures. The violence, in any case, plays itself out in a relatively short period of time. As the expressive riot wanes, very little that is substantive has been accomplished by the rioters, but the riot itself has been a form of communication. The white majority recognizes that local Negro grievances are more serious than they were thought to be, but the more significant reaction is a generalized sense of disturbance and an increase in polarization. The Negro rioters, on the other hand, feel they have made their point and adopt a wait-and-see attitude. Threats and promises are made on both sides, and a few token or symbolic changes are made in the short run; but the basic causes, motives, and objectives are a potential legacy for future outbursts. ${ }^{16}$

16 The major riots in Milwaukee and Tampa, the three serious riots in university settings, and the serious riots in Cambridge and Dayton (June) are the best examples of 
3. The "Reified" Riot of Social "Contagion." The reified riot is a "stimulated" riot in the sense that it is the answer to a self-fulfilling prophecy. Such riots may be subclassified according to the predominant source of the prophecy into (1) media-created riots, (2) authority-created riots, and (3) conformity-created riots on the part of some elements in the Negro community. The reified riot is, essentially, an abstraction made real through the repetition of news about other riots, proximate in space or time, resulting in anticipatory or conforming behavior. The other riots are real enough, but local reports of their nature are filtered through the subjective factors in the grievance banks of both the white and the Negro communities: rumors, propaganda, political agitation and opportunism, charismatic rhetoric, paranoid projections, and the folklore of the streets. Major riots in other cities create satellite riots by a process of communication and social contagion. Reified riots can develop into "rational" or "expressive" riots-indeed, develop in almost any direction-or they may remain indeterminate. At the time of the final incident and the eruption of first violence, they have no "real" character of their own, although they emerge from a social environment that is "ready" for them: enough grievances have accumulated over time and through prior incidents to fill the grievance bank on both sides.

Media-created riots are an unintended consequence of a competitive and narrow functionalism, and a generalized stimulus to the authorityand conformity-created riots. The media conceive of themselves as doing their normal jobs; they are simply "reporting the news" about a nearby riot. In its early stages, however, they are reporting on an emergent situation and thereby helping to shape its definition. At the same time, they are also helping to shape the definition of an incipient local civil disorder that might have remained a routine police action or protest activity. Indeed, the working press and still and television photographers sometimes directly provoke unstable elements among the public and the authorities in order to "manufacture" news. Editorial policies in the selection of headlines, stories, and pictures in an emergent situation overshadow the later background articles and studies "in depth." These policies contribute to the purely subjective factors in the grievance banks of both the white and Negro communities, as well as to rumor and the folklore of the streets.

On the side of authority, reified riots can be said to be "planned for" in the sense that the police and city administrations adopt such a pos-

\footnotetext{
"expressive" riots. The major riot in Milwaukee actually began as a "reified" riot (see note 17 infra) that turned into an "expressive" riot. The serious riot in Atlanta and the minor riot in Dayton (September) also included strong "expressive" themes.
} 
ture of readiness that they create a riot by their anticipatory statements and behavior. The authorities activate their full communication spheres and are intra-stimulated through repetition, preoccupation, and feedback. They are usually in direct contact with some elements of the authority structure dealing with the proximate riot that is the source of news and rumor. Their intention is to be rational and to remain taskoriented, but their focus is too narrow, and they increasingly lose their capacity for making an objective appraisal of all the social forces at play in the local situation. As a result, they are the midwives at the premature birth of a riot.

The conformity-created riot is a direct outgrowth of the two foregoing types, the authority- and media-created. With the background stimulation of a nearby riot, and with the perception of the state of readiness and apprehension on the part of the authorities, youthful and unstable elements in the Negro community in effect say to themselves: "They're expecting it; they're asking for it; let's give it to them." As tension increases with a typical final incident, the reaction seems out of proportion to a routine or trivial event, and the ensuing eruption has the appearance of a "spontaneous" riot. It is, however, the product of the complex interaction between the media, the authorities, and the least stable elements of the public.

Reified riots tend to be short or intermittent and, when intermittent, tend to last about as long as the nearby major riot of which they are a satellite. There are many halo effects from the reports of the proximate riot, as reflected in the perceptions of the local authorities and members of the white and black communities. The intermittent "stop and go" pattern of alternating violence and relative calm is a confused and delayed response to the news as it is received through the media, and through the formal and informal communication spheres that are activated by the authorities and the public. The objectives of the reified riot are short-term and reactive, growing directly out of social interactions in the streets. Such riots can occur anywhere but tend to occur most frequently in middle-sized cities or towns surrounding the central city of a metropolitan region. Participation in these riots involves small numbers if they are contained on the first day. If the reified riot is overreacted to by the authorities or constantly fueled by "atrocity stories" from the proximate major riot, its duration increases and it may become a rational or expressive riot. As the reified riot wanes, the entire community is pervaded by a general sense of disturbance and an increase in polarization as the public comes to realize that "it can happen here." Very little has been accomplished, however; there is no feeling that significant communication has occurred. There is an 
air of unreality about the whole experience and, although threats and promises have been uttered in the course of tactical maneuvering, the situation remains essentially unchanged. No basic causes, motives, or objectives particularly related to the local community have emerged with clarity, the future outlook remains vague, and the white community assumes that the old accommodation patterns will continue to obtain. ${ }^{17}$

4. The "Irrational" Riot of an "Irresponsible" Group. The "irrational" riot is irrational in two senses of the word. It is irrational because it has no real or legitimate objectives. It is not based on any of the more objective factors in the grievance bank, except in a very attenuated sense. It has, therefore, no real causes, but it does have false motives. It is also "irrational" in the sense that it is a stereotyped interpretation of the character of other types of riots, but the stereotype takes the part for the whole and, most frequently, the less important part. Nevertheless, there are irrational components in most riots and, in a few cases, it may be said that irrationality is their predominant character. Irrational riots may be divided into two categories, one of which can be analyzed and explained, and another residual category that can be described but not explained. The former is the "irrational" riot with no legitimate objectives and false motives, and the latter is the pure type of the irrational.

The "counterfeit-irrational" riot is a diversionary maneuver by a group of conspiratorial or simply disorderly persons who are "raising hell." The criminal or conspiratorial groups "stage" some elements of civil disorder in order to achieve some organized and illegitimate purpose. In the case of the disorderly group, the civil disorder is an unintended consequence of exaggerated recreational behavior, like drinking or horseplay. The criminal and conspiratorial activities of such

17 The major riots in Cincinnati, Detroit, and Newark served as the riots of reference in space and time for a whole series of "reified" riots in the metropolitan regions surrounding these cities. While such satellite riots may also be subsumed under other headings, their "reified" character is the predominant element in either the final incident preceding the eruption of violence or their duration or both. The major riot in Milwaukee exhibited strong elements of a "reified" riot, with Detroit as the riot of reference, that developed into an "expressive" riot. The serious riot in Grand Rapids was also a "reification" of the Detroit riot. The "New Jersey string" of riots-Bridgeton, Elizabeth, Englewood, Jersey City and New Brunswick (all minor); the major riot at Plainfield; and the serious riot at Paterson-all reflected "reification" effects from Newark as the riot of reference. The minor riot in Rockford was a "secondary reification" from Milwaukee which was itself a "reified" riot. Four incipient civil disorder incidents from nearby Chicago also cast their "halo effects" over Rockford. Three other "reified" riots whose later predominant character was "expressive" were the serious riots in Cambridge, Dayton (June), and Phoenix. The minor riot in Tucson was a "reified" riot that seemed to remain largely "irrational" (see note 18 infra). 
groups represent an opportunistic expression of long-term "life-styles"; their behavior is the product of some degree of planning and organization among persons who are "professional" criminals or agitators. They and their activities must be sharply distinguished from persons who commit situational crimes in the course of a riot or who engage in short-term tactics in the fluid situation of a riot. The more professional criminals loot not only for personal aggrandizement, but for resale and profit as well. The situational criminal loots mainly for personal aggrandizement, but also out of need created by the disruptions of a riot. Similarly, the more professional conspirator wants to control the course of the riot in order to implement some ideological plan of the extreme left or right, but more frequently than not, he is the captive of the riot rather than the reverse. The short-term tactician, who must be distinguished from the professional conspirator, is at best a would-be negotiator in the more rational discussions that go on in the background of riots or at worst merely provocative or reactive in relation to the authorities in the streets. By and large, insofar as such "irrational" elements succeed in precipitating a civil disorder, the participants are few in number and their activities are quickly brought under control. Otherwise, they are a minor element in a different kind of riot and their motives and activities are confused with more basic social causes, motives, and objectives.

The "pure-irrational" riot is an unintended consequence of the pureirrational activities of individuals or very small groups. It may be an anticipatory or reactive paranoid, striking out blindly at a presumed "enemy," or a random "settling of old scores" as between blacks and whites, or the reaction of unstable personalities to some natural disaster (fire, flood, breakdown of public utilities) which erupts in violence. Such persons and events are essentially unpredictable and unpreventable; they are the by-products of a complex social organization that takes its toll at the weakest points. ${ }^{18}$

5. The Interracial Riot. The interracial riot is the kind of riot that did not happen in 1967, nor, indeed, has there been such a riot in the past twenty-five years. It is a spectre that has haunted Americans whose historical frame of reference is the nineteenth-century rural economy. The nature of race and class relations has undergone a radical shift in character since World War I, and the old-style interracial riots that have taken place since then may well be a historical

18 The minor riot in Tucson had the nearest resemblance to an "irrational" riot of the pure-irrational type. At one stage of the serious riot in Grand Rapids, underworld vice elements almost succeeded in exploiting a "reified" riot by trying to turn it into an "irrational" riot of the counterfeit-irrational type. See NACCD REPoRT at 379. 
holdover from this earlier period. Interracial violence, as one form of social violence, has been well defined by Grimshaw: "Social violence ... refers to assault upon individuals, or their property, solely or primarily because of their membership in social categories."10 This definition encompasses much more than interracial violence, and our earlier ideal-types of the "rational" and "expressive" riots reveal some indications of the shift from racial to class competition.

In recent riots the violence of Negroes was directed against the symbols of the white community: authority and property, rather than the white community as a whole. The violence of whites, while much less discriminating, was still not directed against the Negro community as a whole. The "expressive" riot was accompanied by leadership struggles within the Negro community, and the "rational" riot was accompanied by leadership struggles both within the Negro community and between the Negro and white communities. At the same time, over the past fifty years there has been a gradual increase in the proportion of Negroes who have achieved middle-class status.

From the standpoint of a shift from race to class competition, these historical developments indicate that "expressive" riots may be a transitional type to "rational" riots and that it is the latter that are more likely to occur in the future, unless alternative means to achieve their ends intervene to prevent them. Moreover, regardless of local and transient appearances, this historical development in the United States is essentially a conservative movement. The "rising" Negro class does not want to change the American system; what they are saying and have been saying for the past hundred years is: "We want fuller participation in the goods, services and amenities enjoyed by the vast majority of American citizens."

\section{A Postscript on Communication: "Images of Organization"} ANd "Phantom Snipers"

All civil disorders, anticipated and actual, increase the frequency and intensity of communication among and between the individuals and groups who are most concerned, directly and indirectly. The authorities, in particular, with their immediate and constant access to a large variety of communication methods and their more intimate contacts with the mass media and authorities in other locations, are able to activate an intense and resonating network of communication which we have referred to as their communication sphere. Similarly, the public caught up in anticipatory or actual civil disorders, and those who comprise the wider public audience, also increase the frequency and intensity of their communications. 
The mass media, with their constant and repetitious reporting of the news of civil disorders, feed directly into both the official and public communication spheres. In addition, the authorities, mass media workers, and members of the public have not only formal capacities and relations, but also informal contact with each other. During the course of a major riot these interrelated communication spheres link everyone, from the President down to the lowliest street gang member, in a resonating network of communication and feedback. All of these communications, rational and irrational, contribute to the creation of a "riot climate."

We have seen how, in the case of reified riots, the activation of these official and public communication spheres, together with the unintended effects of the mass media reporting the news, contributes directly to the "creation" of some civil disorders. There is, however, a secondary effect of the relation between the official communication sphere and the mass media that may help to account for the puzzling contradiction between the theory that riots are the products of organization and the absence of evidence of such organization in subsequent investigations. It may also help account for the great disproportion between the large number of reported snipers and the relatively few that are identified or arrested and charged.

We have characterized civil disorders, in their initial stages, as being emergent situations without clear definition. Both local authorities and other observers, confronted with what was perceived as an ambiguously dangerous social situation, tended to define such emergent situations in operational terms for the sake of dealing with an unknown, future, potential situation. Similarly, the mass media, reporting such emergent situations, tended to select the most newsworthy and dramatic elements from developing events. Both the authorities and the mass media were simply doing their jobs; had they not done it, they would have been subject to severe criticism. Nevertheless, the functional rationality ${ }^{20}$ of a narrow or specialized task-orientation had many unintended consequences, one of which was the creation of the image of organization and the multiplication of phantom snipers.

The authorities in their communications, and in their deployment of manpower and other resources, attract the attention of interested

20 K. MANNheim, MAN AND Society (1940), distinguishes between "functional" and "substantial" rationality. "The common soldier, for example, carries out an entire series of functionally rational actions accurately without having any idea as to the ultimate end of his actions or the functional role of each individual act within the framework of the whole." On the other hand, "We understand as substantially rational an act of thought which reveals intelligent insight into the inter-relations of events in a given situation." Id. at 56, 53. It is worth noting that Mannheim associated an increase in "functional rationality" with a tendency toward totalitarianism. 
members of the public. If, for example, five squad cars from three local beats converge on some location, together with two squadrols sent out from the police station, they will attract an audience even though they may simply be responding to a false "officer-needs-help" signal. Reporters coming on the scene somewhat later are apt to pick up the folklore of the streets rather than a real event. Several such false alarms, or small skirmishes, taking place in the atmosphere of a "riot climate," soon begin to take on substance. One of the earliest and simplest explanations of "what is going on" is a theory of conspiracy and organization by a group that was previously perceived as being capable of inciting or agitating a riot.

Somewhat similar processes are at work when the authorities are simultaneously deployed in several locations under a fragmented command or on their own. Any firing of heavy weapons like Stoner rifles and Magnum pistols, whose muzzle velocity sends their missiles through flesh, wood, brick, and metal, creates a dangerously ambiguous

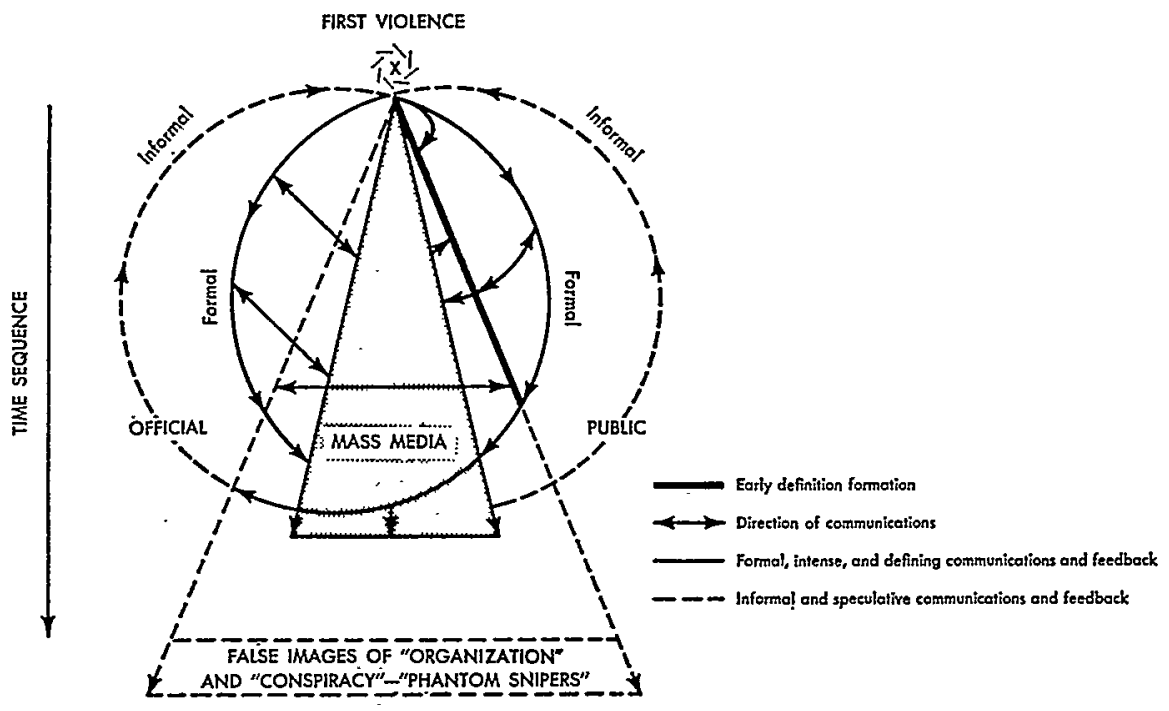

figure 2. The Activation of Official and Public Communication Spheres, the Mass Media, and Mutual Feedback Following upon the OUtbreak of First Violence. In this figure the "operational necessity" of defining the nature of civil disorders in their early, ambiguous, and emergent stages, so that they can be dealt with and reported to the public, results in an interpretation of what first violence means. The simplest and earliest theory is that the developing violence is organized, represents a conspiracy, and is being implemented by snipers. Once the theory is asserted, it is repeatedly fed back to the interest groups engaged in the defining process through the selective perception of "verifying, instances" present in a highly complex event, and the definition begins to crystallize. In process of time, and upon more intensive investigation, however, these "images" grow dim for lack of supporting evidence. The "organization" cannot be described, the participants in the "conspiracy" cannot be identified, and the gunfire seems to emanate from "phantom snipers." For true believers the very lack of objective evidence is simply further. "evidence" of the depth, deviousness, and elusiveness of "organized conspirators and snipers." 
situation for the authorities, rioters, and innocent bystanders near and far. The scene is also set for the inferential creation and multiplication of nonexistent snipers.

Thus the conspiratorial theory and the phantom sniper are fed into the communication spheres of the authorities and the mass media at an early stage, and they keep coming back from what appear to be other, and independent, sources through feedback channels. As a result the images of organization and the phantom sniper are created, projected, and reflected, and they continue to resonate in the atmosphere until more thorough and dispassionate investigation seeks the evidence for them. Insofar as the twenty-four disorders studied by the Commission are concerned, no evidence of conspiracy or organization, whether from the left or the right, or black or white, was uncovered. ${ }^{21}$ Similarly, reports of sniping were found to be highly exaggerated. ${ }^{22}$

21 NACCD REPORT at 89.

22 Id. at 180. 